\title{
Systematic Analysis of Effectiveness of Using Mobile Technologies (MT) in Teaching and Learning Foreign Language
}

\author{
Mahmoud Hawamdeh 1 \\ (D) 0000-0001-5321-2400 \\ Emrah Soykan ${ }^{{ }^{*}}$ \\ (iD) 0000-0002-0385-1404 \\ ${ }^{1}$ Near East University, CYPRUS \\ *Corresponding author: emrah.soykan@neu.edu.tr
}

Citation: Hawamdeh, M., \& Soykan, E. (2021). Systematic Analysis of Effectiveness of Using Mobile Technologies (MT) in Teaching and Learning Foreign Language. Online Journal of Communication and Media Technologies, 11(4), e202124. https://doi.org/10.30935/ojcmt/11256

\section{ARTICLE INFO}

Received: 12 Jun 2021

Accepted: 31 Aug 2021

\begin{abstract}
Although Mobile-Assisted Language Learning (MALL) is rapidly evolving, there is still a lack of research synthesis and systematic meta-analysis. The effectiveness of mobile devices for language learning under various conditions remains unclear. A limited study is carried out on how the latest smartphone devices effectively teach and learn. Mobile technology is the most Information and Communication Technology (ICT) tool used in our daily life for different purposes, including educational purposes. For instance, Mobile Technology (MT) has been significantly used for learning languages because today's students tend to use this technology frequently and almost every hour. This research aimed to explore the effects of mobile devices in foreign language learning and present the sample studies conducted between 2014 and 2021; 100 articles were chosen from Google Scholar, ResearchGate and Science Direct database through using different search keywords. The results of the research revealed that the most examined studies were published in Indonesia and Saudi Arabia. The university students were selected as sample groups in these articles, and that most articles used the experimental research design. The findings also showed that English was the most foreign language examined in these articles, and WhatsApp is the most mobile application used in these articles.
\end{abstract}

Keywords: mobile technology, foreign language teaching, language learning, mobile learning, technology integration

\section{INTRODUCTION}

In the educational environment, different technologies and technical learning solutions are no longer a novelty. The development of digital learning materials and facilities is necessary both for classroom activities and for providing students with independent learning opportunities. Nevertheless, there are many additional resources alongside these tools used in the teaching process to make studying more interesting and inspire students to participate more effectively in developing their skills. Mobile technology has evolved exponentially globally and is becoming an essential provider in any age; it can provide convenient access without the limitations of time and location. There are many new technologies created to enhance and promote the dayto-day lives of human beings.

Mobile Technology becomes one of the most attractive technologies that is widely spread around the globe, and it reflects an innovative education solution. Mobile devices have been increasingly integrated into learning in recent times. The extensive use of Smartphones has changed the traditional method of teaching and learning (Gangaiamaran \& Pasupathi, 2017). Mobile phones are used to navigate and study education materials to interact with fellow students, teachers, or organisations (Cakir, 2015). 
Mobile technology is also called Mobile Aided Language Learning (MALL). It comprises all the devices that facilitate language learning, such as smartphones, MP3 players, and even cell phones (Chinnery, 2006). Nowadays, there are a variety of modern Android applications for learning English via Smartphones and tablets. These applications can promote independent learning, realistic language practice, interactive learning, learner control, and add fun to the learning experience. Students can learn by using devices or gadgets familiar to them (Murugan \& Sai, 2017).

The use of mobile phones and other mobile devices is beginning to affect how learning takes place in various fields and contexts, including language learning. It is helpful to be aware of examples with evidence that mobile technology brings something valuable to the languages teaching and learning experience. A considerable number of studies have been carried out to investigate the effect of Mobile Technology (MT) on learning and teaching foreign languages worldwide. The findings of these studies indicated a positive impact of mobile technology when used for teaching and learning foreign languages. The educational value of smartphone and social media applications combined with the development in digital technology is rising. However, research into the educational use of mobile social media in language learning is still inadequate.

Aim

This study investigates the trends of articles in teaching and foreign language related to mobile technology (MT) published between 2014 and 2021 in the Google Scholar, ResearchGate and Science Direct database. The findings revealed that most research on mobile technologies in foreign language teaching and learning is undertaken in 2020. Most of the studies have been conducted in Indonesia, and Saudi Arabia, the justification for selecting these databases was its free and user-friendly access. Furthermore, it is peerreviewed and has a trusted position in the scholarly community. This study has the following main objectives:

- What is the number of articles for each year of study by country?

- What is the distribution of the studies according to the sample groups?

- What research methods have been used?

- What teaching methods were used in these articles?

- What tools for data collection have been used in the studies?

- What's the field of research?

\section{Mobile Learning (ML)}

The area of Mobile Language Learning is rapidly growing. To this end, an ever-growing field of research has appeared that emphasises the different ways mobile devices are used for language learning (Bachore, 2015). Mobile technology becomes the most helpful tool in ICTs, as per Hashemia et al. (2011). Mobility technology is a crucial part of engaging young adults in learning where more traditional approaches have failed.

Mobile devices are commonly portable, readily available, and affordable. Therefore, mobile learning offers easy access to learning material, particular places and learning time, feedback, and self-test. In addition, it is an attractive and flexible process that encourages and motivates students to study (Gafni et al., 2017).

Kuimova et al. (2018) conducted a study among students to investigate the challenges and benefits of mobile technology and its prospects for foreign languages learning. They found that mobile technology can be a valuable tool for accelerating learning, cultivating collaborative and individual learning experiences, encouraging fruitful interactions, enhancing language practice opportunities and promoting lifelong learning.

Shadiev et al. (2017) analysed the literature on mobile language learning in authentic environments from 2007 to 2016 (March). The studies have shown that there is a growing increase in research in this field. They found that students' attitudes towards using mobile learning technologies for language proficiency were the most common research topics, and the most used technologies were smartphones, mobile phones, and personal digital assistants. In contrast, the most common target language was English as a foreign language. In addition to that, university and primary school as a sample group. 
Persson and Nouri (2018) investigated mobile phones as a tool for supporting the learning of second languages by analysing the diverse developments in research done since 2010. In addition to the positive outcomes of using mobile technologies to enhance second-language learning, the research interest increased in mobile learning applications.

\section{METHODS}

\section{Method of Research}

This is a qualitative research study using a content analysis approach. The goal is to define and assess the use of new technologies to use mobile devices in foreign language teaching and learning. The Science Direct, Google Scholar, and ResearchGate databases were selected, and the year limit for this study was set between 2014 and 2021. The reason for choosing these three databases is due to the relevant information identified from these databases. During the scanning process, the keyword (Mobile Learning for Foreign Language) was written in the search engine.

\section{Data Collection Methods}

This study was carried out in 2021 using some relevant databases. The following headings were used to design an Excel table: titles, year, country, sample group, the research method, data collection tools, application tools used, the teaching method used, results and findings, for each article, as headings for the review of mobile learning journals.

\section{Method of Analysis}

The first compendium of the content analysis methods and goals drawn over time and focused on frequency analysis evaluation was content analysis in communication research (Kivunja \& Kuyini, 2017). Qualitative research is referred to as a non-mathematical process of interpretation conducted to identify and organise concepts and variations in raw data and subsequently to a theoretical explanatory scheme. Qualitative research was facilitated study using intensive and prolonged contact with a "field" or living circumstance. The epistemological factors of this research make the use of qualitative methods of analysis more appropriate. This factor gives the strength of qualitative approaches for collecting information, which makes it easier to describe and explain the conversation (Adam, 2020).

Based on the research objectives, a qualitative methodology approach was employed. The decision to select the quality approach for this study consisted of exploiting that participants can understand attitudes, generate content, translate smaller samples to detailed information, and provide insights into mobile technology in foreign language learning. In particular, the study was conducted throughout the research process (Abdullah, 2019).

\section{Data Analysis}

All data is compiled for each article in the Microsoft Word Package Software based on content analysis criteria. Subsequently, the data reports were categorised, and the frequencies were taken according to the inclusion criteria and the keywords parameters suggested by using filter characteristics.

\section{FINDINGS}

\section{Articles Distribution According to Years of Publication}

As shown in Table 1, the most significant number of research publications on mobile learning in teaching and learning foreign languages was $2020(f=50)$ and the lowest in $2019(f=3)$. Although the study period for 2020, the number of papers released in 2020 still has significant results. It can also be expected that the number of publications will increase after August 2020. 
Table 1. Number of articles according to publication year

\begin{tabular}{lcc}
\hline Publication Year & Frequency & Percentage \% \\
\hline 2020 & 50 & 50 \\
2017 & 14 & 14 \\
2018 & 12 & 12 \\
2014 & 09 & 09 \\
2015 & 08 & 08 \\
2016 & 04 & 04 \\
2019 & 03 & 03 \\
\hline
\end{tabular}

Table 2. The number of articles according to countries

\begin{tabular}{|c|c|c|}
\hline Countries & Frequency & Percentage \% \\
\hline Indonesia & 17 & 17 \\
\hline Saudi Arabia & 12 & 12 \\
\hline Iran & 10 & 10 \\
\hline Malaysia & 7 & 7 \\
\hline Turkey & 6 & 6 \\
\hline Taiwan & 6 & 6 \\
\hline China & 4 & 4 \\
\hline Spain & 4 & 4 \\
\hline USA & 3 & 3 \\
\hline Korea & 3 & 3 \\
\hline Australia & 3 & 3 \\
\hline UK & 2 & 2 \\
\hline Iraq & 2 & 2 \\
\hline Oman & 2 & 2 \\
\hline Palestine & 1 & 1 \\
\hline Salvador & 1 & 1 \\
\hline Russia & 1 & 1 \\
\hline Israel & 1 & 1 \\
\hline Colombia & 1 & 1 \\
\hline Sweden & 1 & 1 \\
\hline German & 1 & 1 \\
\hline Tanzania & 1 & 1 \\
\hline Thailand & 1 & 1 \\
\hline Japan & 1 & 1 \\
\hline Canada & 1 & 1 \\
\hline Egypt & 1 & 1 \\
\hline Ukraine & 1 & 1 \\
\hline Czech & 1 & 1 \\
\hline Vietnam & 1 & 1 \\
\hline Algeria & 1 & 1 \\
\hline Ecuador & 1 & 1 \\
\hline India & 1 & 1 \\
\hline Nigeria & 1 & 1 \\
\hline
\end{tabular}

\section{Articles Distribution According to Countries}

As shown in Table 2, the most significant number of Mobile Learning and Learning Foreign Language publications are in Indonesia ( $f=17)$, Saudi Arabia $(f=12)$, Malaysia $(f=07)$, Turkey and Taiwan $(f=06)$, China and Spain $(f=4)$, US, Korea, and Australia $(f=03), U K$, Iraq, and Oman $(f=02)$. At the same time, 19 other countries had less with $(f=01)$.

\section{Sample Group}

Table 3 shows that university students were the most used sample group $(f=71)$. The second highest sample group was High School Students $(f=08)$, and the third-highest was Adults \& Teachers $(f=07)$. Primary school students $(f=04)$ and pre-school students $(f=03)$ were the lowest sample groups. 
Table 3. The number of articles according to sample groups

\begin{tabular}{lcc}
\hline Sample Group & Frequency & Percentage \% \\
\hline University Students & 71 & 71 \\
Adults & 7 & 7 \\
Secondary School Students & 4 & 4 \\
Teachers & 7 & 7 \\
Pre-School Students & 3 & 3 \\
High School Students & 8 & 8 \\
\hline
\end{tabular}

Table 4. The number of articles according to the research method

\begin{tabular}{lcc}
\hline Research Methods & Frequency & Percentage \% \\
\hline Mixed Method - Case Study & 24 & 24 \\
Qualitative - Case Study & 15 & 15 \\
Qualitative - Action Research & 6 & 6 \\
Quantitative - experimental & 35 & 35 \\
Quantitative - Survey & 20 & 20 \\
\hline
\end{tabular}

Table 5. Number of articles according to the tools of data collection

\begin{tabular}{lcc}
\hline Data collection tools & Frequency & Percentage \% \\
\hline Questionnaire & 52 & 36 \\
Test & 38 & 26 \\
Interview & 33 & 23 \\
Observation & 19 & 13 \\
Others (Documents, dairies, Notes, log files) & 3 & 2 \\
\hline
\end{tabular}

Table 6. Number of articles according to foreign languages

\begin{tabular}{lcc}
\hline Foreign languages & Frequency & Percentage \% \\
\hline English & 85 & 85 \\
German & 3 & 3 \\
French & 3 & 3 \\
Mandarin & 2 & 2 \\
German, French and Chinese & 1 & 1 \\
German and French & 1 & 1 \\
Swedish & 1 & 1 \\
Arabic & 1 & 1 \\
Chinese & 1 & 1 \\
Japanese & 1 & 1 \\
Malay & 1 & 1 \\
\hline
\end{tabular}

\section{Articles Distribution According to Research Methods}

The Quantitative - experimental studies were the most adopted $(f=35)$, as shown in Table 4. The second highest result was Mixed Method - Case Study ( $f=24)$, followed by Quantitative - Survey ( $f=20)$, and Qualitative - Case Study ( $f=15)$. The Qualitative - Action Research $(f=06)$ was the least.

\section{Data Collecting Tools Used in the Article}

The most studied used more than one data collection tool; the questionnaire was the most used tool for data collection ( $f=52$ ), as shown in Table 5. Alongside this, the second-highest result is used a pre-and posttest $(f=38)$, which is usually used to collect quantitative data. The interview has been used ( $f=33$ ) followed by observation ( $f=19$ ) in collecting qualitative data.

\section{Foreign Languages According to the Articles}

As shown in Table 6, the English language has the highest number $(f=85)$, following are the German and French languages $(f=03)$ and Mandarin $(f=02)$, while Swedish and some combination of German, French, Chinese, Arabic, Japanese, and Malay $(\mathrm{f}=01)$ is least. 
Table 7. Number of articles according to used mobile applications

\begin{tabular}{lcc}
\hline Mobile Application & Frequency & Percentage \% \\
\hline WhatsApp & 26 & 34 \\
Online Dictionary & 12 & 7 \\
Duolingo & 5 & 5 \\
Podcasts & 4 & 4 \\
Google Translator & 3 & 4 \\
Telegram & 3 & 4 \\
Augmented Reality App & 3 & 3 \\
Quizlet & 2 & 3 \\
Formative & 2 & 1 \\
Detective ABC & 1 & 1 \\
KakaoTalk & 1 & 1 \\
MP3players & 1 & 1 \\
Guess it! & 1 & 1 \\
ASR application & 1 & 1 \\
Audio News Trainer (ANT) & 1 & 1 \\
Flubaroo & 1 & 1 \\
Digital media players & 1 & 1 \\
German Grammar Guide and a Pronunciation App & 1 & 1 \\
Penultimate & 1 & 1 \\
UIC German & 1 & 1 \\
NGSL App & 1 & 1 \\
Sound-to-Speak & 1 & 1 \\
MLBP & 1 & 1 \\
Dialang & 1 & 1 \\
WeChat & 1 & 1 \\
MAS & 1 & 1 \\
TED & 1 & 1 \\
i-Tune & 1 & 1 \\
audiobook & 1 & 1 \\
\hline
\end{tabular}

Table 8. Number of articles according to used mobile devices

\begin{tabular}{lcc}
\hline Mobile device & Frequency & Percentage \% \\
\hline Smartphone & 77 & 76 \\
Mobile Phone & 17 & 17 \\
iPad & 5 & 5 \\
iPod Touch & 1 & 1 \\
MP3 players & 1 & 1 \\
\hline
\end{tabular}

\section{Mobile Applications Used in the Articles}

80 Articles out of 100 mentions the use of mobile applications, as shown in Table 7. WhatsApp is the most commonly used $(n=24)$, which represents $(34 \%)$ of the articles reviewed in this study, followed by the online dictionary applications $(n=12)$ articles (16\%). Five articles (6\%) used Duolingo, and four articles (5\%) used Podcasts. Google translator, Telegram, Augmented Reality App was used by three articles (4\%), and two articles (3\%) used Quizlet and Formative. The rest of the articles $(n=1)(1 \%)$ used various mobile applications.

\section{Mobile Devices Used in Foreign Languages Learning.}

Mobile phones and smartphones are mobile devices that are used to call and send texts. This is where a mobile telephone stops, too, although a camera is also included. A smartphone features extra functions, such as an Internet connection, an app download option and a camera (typically better). This allows email to be answered by telephone and photographs to be shared. Another difference is that mobile phones frequently feature a physical keyboard, whereas smartphone keyboards are usually virtual. Therefore, mobile devices used for the foreign language are presented in Table 8. Hence, the most used machine in these articles was the smartphone $(n=77)$ articles $(76 \%)$. The mobile phone was used in 17 articles $(17 \%)$, and the iPad was used in 5 articles (10\%). The least used devices were iPod touch and MP3 Player $(n=1)(1 \%)$. 
Table 9. The number of articles according to the learning methods

\begin{tabular}{lcc}
\hline Learning Methods & Frequency & Percentage \% \\
\hline Face to face & 95 & 95 \\
Distance learning & 3 & 3 \\
Blending Learning & 2 & 2 \\
\hline
\end{tabular}

Table 10. The results of tables

\begin{tabular}{llccc}
\hline$\#$ & Criteria & Subject Areas & Frequency & Percentage \% \\
\hline 1 & Years & 2020 & 50 & 50 \\
2 & Country & Indonesia & 17 & 17 \\
3 & Sample Group & University Students & 71 & 71 \\
4 & Research Methods & Experimental & 35 & 35 \\
5 & Data Collecting Tools & Questionnaire & 52 & 52 \\
6 & Foreign languages & English & 85 & 85 \\
7 & Mobile Applications & WhatsApp & 26 & 34 \\
8 & Mobile Devices & Smartphone & 77 & 77 \\
9 & Learning Methods & Face to Face & 95 & 95 \\
\hline
\end{tabular}

\section{The Articles According to Learning Methods}

As shown in Table 9, the Traditional face-to-face methods had the most significant number of articles $(f=95)$ based on the results of the article's analysis. Distance learning was the next with a frequency $(f=03)$, and the last was blended learning with a few numbers of articles $(f=02)$.

\section{Result Table}

As shown in Table 10, among the articles published in 2020 is the highest $(f=50)$, Indonesia's most frequently published country $(\mathrm{f}=17)$. University students are the most of whom are selected as sample groups for the research $(f=71)$. Experimental as research methods with $(f=35)$, the questionnaire as data collection tools $(f=52)$, the most frequently used foreign language is the English language $(f=85)$. WhatsApp is a mobile application $(f=26)$, and the smartphone is a mobile device, while the face-to-face is a teaching method with frequency $(f=95)$.

\section{DISCUSSION AND CONCLUSION}

According to the search engine investigation, for the years between 2014 and 2020, a significant amount of research has been carried out on mobile technology used in teaching and learning foreign languages. The year 2020 has the highest volume of studies; most studies have been undertaken in Indonesia and have been carried out with university students, and the English Language is the most foreign language used in the selected articles. While WhatsApp is a mobile application and Smartphones as mobile devices.

This was also highlighted by a vast number of articles coded by Persson and Nouri (2018) and pointed out that higher motivation positively impacts students with medium-low language proficiency. Their results have shown that flexibility in accessing learning materials in various contexts transforms students from passive to active.

The results showed that the experimental research method was applied in half of the articles (50\%), and mostly these articles used quantitative methods as tools for data collection. Only a few articles used focus groups and application development methods. The researchers employed experimental design as mobile learning research emerged as developed applications (Soykan \& Uzunboylu, 2015). In addition to that, the experimental research method is regularly considered the best type of research design to examine the effect of variables. Viberg and Grönlund (2012) accentuated that the Experiment' is the most methods in the studies they reviewed (47\%), and they found that the majority of these studies are small scale, exploratory, and led inside a brief timeframe, which makes them somewhat recounted as far as reliability.

The analysis of the articles shows that the students of universities were (68\%) targeted as a sample group in the studies, and Persson and Nouri (2018) emphasised that most of the studies were intended to demonstrate the influence of mobile technology in second language learning with a particular emphasis on 
its integration in higher education. A few articles focus on informing independent learning and secondary school learners. The research on Informal language learning as well as elementary and high school learners is still lacking. Shadiev et al. (2017) clarified this finding that university students had their mobile devices, and they required skills, competency, and experience to use mobile technologies for learning. There is no need to buy a mobile and learn how to use this technology.

Furthermore, although few articles examined other languages such as German and French (6\%), English language was the most examined language in these articles (82\%); this is probably normal as English is the first international language in the world, especially in the countries where the reviewed articles conducted. For instance, most reviewed articles were conducted in Saudi Arabia (12\%), whereas English was considered an essential and required skill. It is shown that $84.9 \%$ of Saudis learn English to get a job with a better salary (Alkubaidim, 2014). This also has been discovered by Shadiev et al. (2017), and they clarified that the English language is the most popular nowadays, and the international students of the English language need an inclusive learning environment to study a foreign language.

Articles from Indonesia had 17\%, which is the highest in this study. This is due to the penetration of smartphones in Indonesia, which has continued to expand in recent days since it enhances education quality. There are several methods of smartphone-based learning in Indonesia, such as; sound learning, short text messages, learning via a graphic display, learning from data, learning through an Internet search and learning via camera and video clips (Katemba, 2021; Machmud, 2018). Therefore, university students in Indonesia utilise smartphones every time they participate in courses, including in the lecture room (Katemba, 2019; Katemba \& Sinuhaji, 2021; Morissan, 2021).

WhatsApp (32\%) was the most used mobile application in these articles because it is the most popular application for students. One of its advantages is reducing anxiety and practising pronunciation and speaking (Costa \& Han, 2017). The most technology used was the Smartphone $(n=27)$ articles $(54 \%)$, followed by mobile phone (Smart Phones, Camera Phones, and 4G/5G Phones) used ( $n=17$ ) articles (34\%). More articles smartphones are because smartphones are forms of multipurpose computer-based mobile telephones with numerous functionalities such as high-end hardware and operating systems, software, Internet and multimedia with basic telephone operations, and many more upgrades. Each person now uses a mobile device since the mobile phone comes with various functions and varied rates. Smartphones are available with every feature anywhere in the world. Smartphone has one more benefit which allows students to learn the stuff they want. Because smartphones are very popular with students nowadays, it becomes easier than passing through the pages of a book to make a point plain to a student via a phone. Smartphones are used intelligently for audio and video learning as it is exciting and dynamic. And it's an efficient means of teaching complicated subjects. This corresponds to the results of another study, which reported that the most commonly used devices were smartphones, followed by mobile phones, and stated the reason for this because of their advanced capacities, which allowed students to do much more than any other mobile device (Shadiev et al., 2017).

Several articles on the use of mobile devices in the various fields of language teaching and learning have reinforced the belief that mobile technology will improve foreign language learning for students (Bourekkache et al., 2020, Busch \& McCarthy, 2021; Ishaq et al., 2021; Laurens \& Valdés, 2021; Sletten, 2021; Sun et al., 2020; Viberg \& Grönlund, 2012). This is also emphasised by some of the selected articles reviewed in the present study, which revealed that students' language skills improved after using mobile technology. Students have demonstrated positive attitudes towards using mobile devices to learn a foreign language (Alkubaidim, 2014; Bourekkache et al., 2020; Busch \& McCarthy, 2021; Ishaq et al., 2021; Laurens \& Valdés, 2021; Shadiev et al., 2017; Sletten, 2021; Viberg \& Grönlund, 2012).

This study analysed the articles on the use of mobile devices in the teaching and learning of foreign languages, which highlights the current state of the art. This content analysis has made it possible to explain the significant effects of the use of mobile devices to promote the teaching and learning of foreign languages. In addition to the trends in research, such as an increasing interest in the development of mobile learning.

Most of the reviewed studies focused on incorporating mobile technologies among university students; however, there is still a need for research on informal language learning. The content analysis also revealed 
a trend to investigate mobile technologies as tools to teach the English language, under-representing how mobile technologies can teach other foreign languages.

Mobile applications for foreign language teaching and learning are a field that also needs more investigation. Further research will help to study in-depth how emerging apps will promote other language learning and mobile application studies to develop under-represented language skills. In addition, more advanced intelligent technologies are now available, such as robotics, a virtual reality that we recommend to be considered in future research.

We, therefore, suggest that other technologies be included. More advanced technology nowadays exists and can be used to support language learning and teaching.

In recent studies, we have noticed a shift in focus. Instead of focusing on the entire mobile phone, researchers are increasingly focusing on smartphones as the significant application for foreign learning in most Universities (Sun et al., 2020). Chen and Tsai (2020) study believed that further study is war-ridden because the smartphone is a multi-functional instrument for various types of users. Instead of focusing on diverse applications such as instant communication, messaging, cyber-loafing, competing with others and so forth, a taxonomy of different sorts of use may be developed (Bourekkache et al., 2020; Elaish et al., 2017). This inquiry should also answer how smartphones are affected by the context. The extant study does not mainly describe the context of involved smartphone users, such as private, working-related and education use in the classroom (Laurens \& Valdés, 2021).

However, recent research has shown that high smartphone levels will not inevitably lead to problems for the user (Alisultanova et al., 2020). Therefore, it is likely that quantifying the normative use as time-consuming a smartphone is fundamentally defective as it varies according to functions, user motives, devices throughout the ages, sexes, cultures, etc. (Bourekkache \& Kazar, 2020). Huzairin et al. (2020) believe that academics should be more carefully considered and encouraged to study the 'how' and 'why' of use (e.g., standard smartphones in various situations) and not 'how much (e.g., at which smartphone levels smartphones are typical and how difficult their use is) to use. This is of particular interest, given the socially accepted use of smartphones (Sletten, 2021).

Our analysis showed that smartphones are used across the world as a means of learning a foreign language. Therefore, it is necessary to study more why smartphone use is motivated and why it is tough to use it separately (Ishaq et al., 2020a). In contrast, smartphone usage might be defined as a logical decisionmaking process based on attitudes (Busch \& McCarthy, 2021).

The smartphone usage of students is both negatively and beneficial depends on how it is utilised, according to Buttazzoni et al. (2021). The author further stresses that the smartphone has become a big distraction from studying on the wrong sides of the coin. For example, students attached to their smartphones have a high propensity to check or notify changes virtually every minute if not closely regulated. The author found that cellphones have a mixture of academic achievement or student teaching (Ishaq et al., 2020b).

Ishaq et al. (2020c) have suggested that, despite the smartphone's physical advantage of learning a foreign language, it is seen as a double-edged sword where some experience adverse effects due to the addictive character of most applications such as WhatsApp, Facebook and Games. It steals students' time accidentally, which severely impact their academic achievement. Similarly, Klimova and Poláková (2020) evaluated smartphone dependence among college students and their involvement in learning among students. The study indicated high-risk addictions, resulting in low self-regulated smartphones. Similarly, Buttazzoni et al. (2021) concur with this research that smartphones spend most users' time and don't.

Mobile phones were more effective than others in the various methods of the acquisition of English. The research papers on this topic have indicated increased improvements in the performance of foreign language learners and combined application studies (Sletten, 2021).

The paradigm of technology-supported classrooms has changed mobile devices and related technologies. The use of such technologies can contribute to the accomplishment and retention of learners, support all levels of learning difficulties, and reach students who otherwise would not be able to take part in education (Buttazzoni et al., 2021). 
These findings demonstrated mobile telephones could also be utilised as a tool for learning, not simply for enjoyment, communication and entertainment purposes. They support creative work in foreign language courses in particular. Students often have a good mobile learning attitude and encourage engagement in talks with their fellow students and the school teacher (Yu \& Yu, 2021). The students also indicated that they enjoyed interaction and cooperation in the performance of assignments, the discussion of views and English practice when conducting WhatsApp work (Sletten, 2021). The use of smartphones has provided the opportunity to use the target language through the innovative use of mobile learning and has contributed to more effective learning, enhanced academic achievement and communication in the learning process (Machmud, 2018). Through this study, the use and understanding of smartphones were discussed and the effective use of mobile phones as a tool for learning foreign languages across the globe.

Finally, this study is limited to the number of articles reviewed and the databases used to search these articles. Further research can use more databases and examine more articles.

Author contributions: All authors were involved in concept, design, collection of data, interpretation, writing, and critically revising the article. All authors approve final version of the article.

Funding: The authors received no financial support for the research and/or authorship of this article.

Declaration of interest: Authors declare no competing interest.

Data availability: Data generated or analysed during this study are available from the authors on request.

\section{REFERENCES}

Abdullah, K. S. S. (2019). Research paradigm and the philosophical foundations of a qualitative study. PEOPLE: International Journal of Social Sciences, 4, 1386-1394. https://doi.org/10.20319/pijss.2019.43.13861394

Adam, A. M. (2020). Sample Size Determination in Survey Research. Journal of Scientific Research \& Reports, 26(5), 90-97. https://doi.org/10.9734/JSRR/2020/v26i530263

Adamu, I., \& Soykan, E. (2019). Content analyses on the use of technology in dyslexia: The articles in the Web of Science database. International Online Journal of Education and Teaching (IOJET), 6(4). 789-797. http://iojet.org/index.php/IOJET/article/view/670

Alisultanova, NS., Isaeva, M., \& Boltiev, D. (2020). Teaching and learning foreign languages using ICT. Bulletin of GGNTU. Humanities and Socio-economic Sciences, 60-66. https://doi.org/10.34708/GSTOU.2020.39.99.008 [In Russian]

Alkubaidi, M. (2015). The relationship between Saudi English major university students' writing performance and their learning style and strategy use. English Language Teaching, 7(4), 83-95. https://doi.org/10.5539/ELT.V7N4P83

Bachore, M. M. (2015). Language learning through mobile technologies: An opportunity for language learners and teachers. Journal of Education and Practice, 6(31), 50-53.

Bourekkache, S., \& Kazar, O. (2020). Mobile and adaptive learning application for English language learning. International Journal of Information and Communication Technology Education: An Official Publication of the Information Resources Management Association, 16, 36-46. https://doi.org/10.4018/IJICTE.2020040103

Bourekkache, S., Tigane, S., Kazar, O., \& Kahloul, L. (2020). Mobile and personalised learning system for computer science students. 2020 Sixth International Conference on e-Learning (econf). https://doi.org/10.1109/econf51404.2020.9385476

Busch, P. A., \& McCarthy, S. (2021). Antecedents and consequences of problematic smartphone use: A systematic literature review of an emerging research area. Computers in Human Behavior, 114, 106414. https://doi.org/10.1016/j.chb.2020.106414

Buttazzoni, A., Brar, K., \& Minaker, L. (2021). Smartphone-based interventions and internalising disorders in youth: Systematic review and meta-analysis. Journal of Medical Internet Research, 23, 1-12. https://doi.org/10.2196/16490

Chen, C., \& Tsai, C. (2021). In-service teachers' conceptions of mobile technology-integrated instruction: Tendency towards student-centred learning. Computers \& Education, 170, 104224. https://doi.org/10.1016/j.compedu.2021.104224

Chinnery, G. M. (2006). Going to the MALL: Mobile-assisted language learning. Language Learning \& Technology, 10(1), 9-16. http://lt.msu.edu/vol10num1/emerging/ 
Elaish, M., Shuib, L., Ghani, N., Yadegaridehkordi, E., \& Alaa, M. (2017). Mobile learning for English language acquisition: Taxonomy, challenges, and recommendations. IEEE Access, 1-1. https://doi.org/10.1109/ACCESS.2017.2749541

Gafni, R., Achituv, D. B., \& Rachmani, G. J. (2017). Learning foreign languages using mobile applications. Journal of Information Technology Education: Research, 16, 301-317. https://doi.org/10.28945/3855

Hashemi, M., Azizinezhad, M., Najafi, V., \&Nesari, A. J. (2011). What is mobile learning? Challenges and capabilities, Procedia - Social and Behavioral Sciences, 30(2011), 2477-2481. https://doi.org/10.1016/j.sbspro.2011.10.483

Huzairin, Hu., Putrawan, G. E., \& Riadi, B. (2020). Technology and language learning: English as a foreign language learners' use of smartphones for informal online learning in Indonesia. Texto Livre: Linguagem e Tecnologia, 13, 103-120. https://doi.org/10.35699/1983-3652.2020.24657

Ishaq, K., Azan, N., Rosdi, F., Abid, A., \& Ali, Q. (2020a). Usability of mobile assisted language learning app. International Journal of Advanced Computer Science and Applications, 11. https://doi.org/10.14569/IJACSA.2020.0110145

Ishaq, K., Azan, N., Rosdi, F., Abid, A., \& Ali, Q. (2020b). The usefulness of Mobile Assisted Language Learning in Primary Education. International Journal of Advanced Computer Science and Applications, 11. https://doi.org/10.14569/IJACSA.2020.0110148

Ishaq, K., Mat, Z. A. N., Rosdi, F., Jehanghir, M., Ishaq, S., \& Abid, A. (2021). Mobile-assisted and gamificationbased language learning: a systematic literature review. PeerJ Computer Science, 7, 1-57. https://doi.org/10.7717/peerj-cs.496

Ishaq, K., Rosdi, F., Azan, N., \& Abid, A. (2020c). Usability and design issues of mobile assisted language learning application. International Journal of Advanced Computer Science and Applications, 11, 86-94. https://doi.org/10.14569/IJACSA.2020.0110611

Ismail, C. (2015). Opinions and attitudes of prospective teachers for the use of mobile phones in foreign language learning, Contemporary Educational Technology, 6(3), 239-255. https://doi.org/10.30935/cedtech/6152

Katemba, C. (2019). Students' vocabulary enhancement at grade 10: A comparative study using CALL \& MALL in Indonesia. CALL-EJ, 20, 87-114.

Katemba, C. V. (2021). Enhancing vocabulary performance through mobile assisted language learning at a rural school in Indonesia. Acuity: Journal of English Language Pedagogy, Literature and Culture, 6(1), 1-11. https://doi.org/10.35974/acuity.v6i1.2457

Katemba, C. V., \& Sinuhaji, G. V. (2021). Can ESA method through quizizz games enhance vocabulary knowledge? International Journal of Game-Based Learning (IJGBL), 11(3), 19-37. https://doi.org/10.4018/IJGBL.2021070102

Kivunja, C., \& Kuyini, A. B. (2017). Understanding and applying research paradigms in educational contexts. International Journal of Higher Education, 6(5), 26-41. https://doi.org/10.5430/ijhe.v6n5p26

Klimova, B., \& Poláková, P. (2020). Students' perceptions of an EFL vocabulary learning mobile application. Education Sciences, 10, 37. https://doi.org/10.3390/educsci10020037

Kuimova, M., Burleigh, B., Uzunboylu, H., \& Bazhenov, R. (2018). Positive effects of mobile learning on foreign language learning, TEM Journal, 7(2), 837-841. https://doi.org/10.18421/TEM74-22

Laurens, L., \& Valdés, H. (2021). M-learning adapted to the ARCS model of motivation and applied to a kinematics course. Computer Applications in Engineering Education. https://doi.org/10.1002/cae.22443

Machmud, K. (2018). The smartphone use in Indonesian schools: The high school students' perspectives. Journal of Arts and Humanities, 7, 33. https://doi.org/10.18533/journal.v7i3.1354

Morissan (2020). The influence of smartphone use on academic performance among Indonesian university students. Jurnal Komunikasi: Malaysian Journal of Communication Jilid, 36(3), 83-101. https://doi.org/10.17576/JKMJC-2020-3603-06

Murugan, A., \& Sai, G. T. B. (2017). The wonders of technology in teaching and learning English. Indonesian EFL Journal, 3(1), 57-68. https://doi.org/10.25134/ieflj.v3i1.654

Persson, V., \& Nouri, J. (2018). A systematic review of second language learning with mobile technologies, International Journal of Emerging Technologies in Learning (iJET), 13(2), 188-210. https://doi.org/10.3991/ijet.v13i02.8094 
Rebeca, S. C., \& Han, T. (2017). The effect of using a mobile application on EFL learners'. International Journal for Developmental and Educational Psychology, $229-238$. https://doi.org/10.17060/ijodaep.2017.n1.v2.935

Shadiev, R., Hwang, W.-Y., \& Huang, Y.-M. (2017). Review of research on mobile language learning in authentic environments. Computer Assisted Language Learning, 30(3-4), 284-303. https://doi.org/10.1080/09588221.2017.1308383.

Sletten, M. A. (2021). Mobile-Assisted Language Learning: Ubiquitous Language Learning and an Examination of the Mobile Learning Environment. In M. Montebello (Eds.), Digital Pedagogies and the Transformation of Language Education (pp. 122-136). IGI Global. http://doi.org/10.4018/978-1-7998-6745-6.ch006

Soykan, E., \&Uzunboylu, H. (2015). New trends in mobile learning area: The review of published articles on mobile learning indirect science database. World Journal on Educational Technology, 7(1), 31-41. https://doi.org/10.18844/wjet.v7i1.22

Sun, C., Yao, Y., Wang, R., \& Ye, X. (2020). A study on the influence of scene reality of VR environment on English learners' learning engagement and learning effectiveness. 2020 IEEE 2nd International Conference on Computer Science and Educational Informatization (CSEI), 2020, pp. 181-185. https://doi.org/10.1109/CSEI50228.2020.9142520

Traxler, J., Elena, B., \& Laborda, J. G. (2015). Mobile technology for foreign language teaching: Building bridges between non-formal and formal scenarios. Journal of Universal Computer Science, 21(10), 1234-1247.

Viberg, O., \& Grönlund, A. (2012). Mobile-assisted language learning: A literature review. 11th World Conference on Mobile and Contextual Learning.

Yang, J., \& Chang, K. S. (2015). How effective are mobile devices for language learning? A meta-analysis. Educational Research Review, 16(2015), 68-84. https://doi.org/10.1016/j.edurev.2015.09.001

Yu, L., \& Yu, Z. (2021). A Comprehensive Review of Mobile Technology-Assisted English Learning. In J. Zhao, \& J. Richards (Ed.), E-Collaboration Technologies and Strategies for Competitive Advantage Amid Challenging Times (pp. 246-265). IGI Global. http://doi:10.4018/978-1-7998-7764-6.ch009

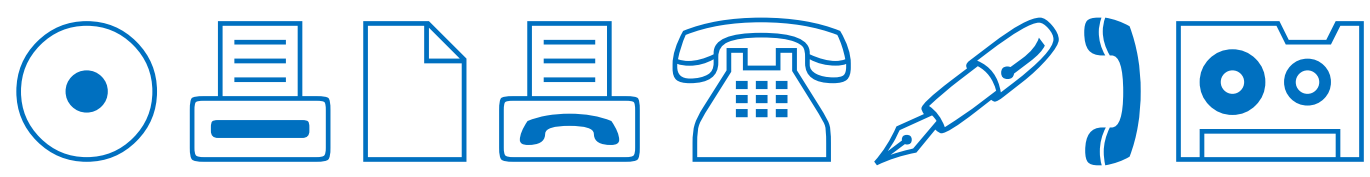

